\title{
Efficacy of needle-placement technique in radiofrequency ablation for treatment of lumbar facet arthropathy
}

This article was published in the following Dove Press journal:

Journal of Pain Research

7 October 2015

Number of times this article has been viewed

\author{
Jeffrey T Loh' \\ Andrea L Nicol' \\ David Elashoff ${ }^{2}$ \\ F Michael Ferrante' \\ 'Department of Anesthesiology, \\ David Geffen School of Medicine, \\ ${ }^{2}$ Department of Biomathematics, \\ University of California Los Angeles, \\ Los Angeles, CA, USA
}

Background: Many studies have assessed the efficacy of radiofrequency ablation to denervate the facet joint as an interventional means of treating axial low-back pain. In these studies, varying procedural techniques were utilized to ablate the nerves that innervate the facet joints. To date, no comparison studies have been performed to suggest superiority of one technique or even compare the prevalence of side effects and complications.

Materials and methods: A retrospective chart review was performed on patients who underwent a lumbar facet denervation procedure. Each patient's chart was analyzed for treatment technique (early versus advanced Australian), preprocedural visual numeric scale (VNS) score, postprocedural VNS score, duration of pain relief, and complications.

Results: Pre- and postprocedural VNS scores and change in VNS score between the two groups showed no significant differences. Patient-reported benefit and duration of relief was greater in the advanced Australian technique group ( $P=0.012$ and 0.022 , respectively). The advanced Australian technique group demonstrated a significantly greater median duration of relief ( 4 months versus 1.5 months, $P=0.022$ ). Male sex and no pain-medication use at baseline were associated with decreased postablation VNS scores, while increasing age and higher preablation VNS scores were associated with increased postablation VNS scores. Despite increasing age being associated with increased postablation VNS scores, age and the advanced Australian technique were found to confer greater patient self-reported treatment benefit.

Conclusion: The advanced Australian technique provides a significant benefit over the early Australian technique for the treatment of lumbar facet pain, both in magnitude and duration of pain relief.

Keywords: low-back pain, lumbar facet arthropathy, interventional pain management, radiofrequency ablation

\section{Introduction}

Chronic pain is a widespread disorder with a prevalence of $2 \%-40 \%$ in the US. In individuals suffering from chronic pain, $28 \%$ complain of low-back pain. ${ }^{1}$ Excluding nonstructural causes of pain, low-back pain can arise from multiple areas: the intervertebral discs of the spine, the zygapophysial (facet) joints of the spine, and the paravertebral muscles, ligaments, and fascia. ${ }^{2,3}$ Postmortem studies have revealed that intervertebral discs and zygapophysial joints exhibit the greatest degree of degeneration within the spine, thus indicating the potential role of these structures in causing low-back pain. ${ }^{4}$ In patients with a structural cause of low-back pain, 15\% of cases arise from the lumbar facet joints., 5 The etiology of lumbar facet-joint pain is thought to result from repetitive stress and trauma to the joint, leading to
Correspondence: Andrea L Nicol Department of Anesthesiology, University of Kansas Medical Center, 390I Rainbow Boulevard - mail stop 1034, Kansas City, KS 66I60, USA

Tel + I 9135886670

Fax + I 9135883365

Email anicol@kumc.edu 
inflammation and stretching of the joint capsule. ${ }^{6}$ Treatment options range from conservative management with the use of medications and physical therapy to interventional management with the use of intra-articular facet-joint injections and radiofrequency ablation of the nervous innervation to the facet joints. ${ }^{6-9}$

Multiple studies have been performed assessing the efficacy of radiofrequency ablation to denervate the facet joint as an interventional means of treating low-back pain. ${ }^{10-14}$ In these studies, varying procedural techniques were utilized to ablate the nerves that innervate the facet joints. The early Australian technique described by Bogduk and Long in 1980 targets the dorsal surface of the transverse process just caudal to the most medial end of the superior edge of the transverse process. ${ }^{15}$ The advanced Australian technique described by the International Spine Intervention Society uses a steep caudocephalad axial tilt of the fluoroscopy beam with a $20^{\circ}$ lateral tilt to allow the radiofrequency-ablation needle to hug the anterolateral aspect of the base of the superior articular process. ${ }^{16}$ Multiple papers have detailed the anatomic course of the nerves that innervate the facet joints. ${ }^{15,17,18} \mathrm{~A}$ recent review compared the anatomic and technical accuracy of the different procedural techniques in treating lumbar facet arthropathy, and described the advanced Australian technique as being the most anatomically appropriate technique. ${ }^{19}$ Currently, there is no available literature comparing the efficacy of the early Australian versus the advanced Australian facet joint-denervation technique.

In this study, we sought to examine the efficacy of the early Australian technique and the advanced Australian technique in terms of patient pain relief, both quantitative and subjective, as well as duration of relief. The rate of complications, the need for follow-up procedures, and whether patient factors affected outcomes were also assessed to determine which technique provided better patient safety and outcome.

\section{Materials and methods Study population}

Prior to data collection, this retrospective chart review was approved by our institutional review board. Prior to retrospective chart review and data collection, the study was reviewed and approved by the Institutional Review Board at the University of California Los Angeles. Given the retrospective nature of the study and large patient cohort, an informed consent waiver was obtained. Patients who underwent lumbar facet radiofrequency denervation between the years of 2008 and 2012 at our outpatient University Pain Management Clinic and presented for at least one follow-up encounter were identified and included in this study. As this study spans 4 years, many individuals received repeat facet radiofrequency denervation procedures. To allow for a more appropriate comparison between the two radiofrequency denervation techniques and to better assess the baseline efficacy, only data for the initial facet radiofrequency denervation of each patient was used for analysis.

\section{Procedural considerations}

All procedures during the study time period were performed by American Board of Anesthesiology, Pain Medicine subspecialty board-certified, pain-management physicians, all of whom were fellowship-trained.

Patient selection in our practice commences with an in-person history and physical examination. Should the patient have a history and physical exam consistent with facet-related pain syndrome, it is standard practice at our facility to perform one set of diagnostic lumbar facet medial branch nerve blocks prior to proceeding with lumbar facet radiofrequency denervation. It is standard practice at our facility among all practitioners that the medial branch nerve block is performed with $1 \mathrm{~mL}$ of long-acting local anesthetic $(0.25 \%$ bupivacaine) given through each needle. The two branches of medial branch nerves that innervate the facet joint are always targeted for both diagnostic blocks and denervation. At a follow-up visit shortly after the procedure, patients who reported greater than $75 \%$ pain reduction during the time frame that the local anesthetic was active were then considered to be candidates for the denervation procedure. All patients included in this study met this criteria prior to their denervation procedure.

Needle placement for the radiofrequency denervation procedure was performed using either the early Australian technique or the advanced Australian technique. Radiofrequency cannulas used for the procedure were either 18 or 20 gauge, with a $10 \mathrm{~mm}$ active tip. Technique after needle placement was consistent among all providers for all patients. After cannulas were placed, motor and/or sensory electrical testing was used to confirm that the needle was not positioned near the spinal nerve or ventral ramus. Once this was confirmed, $1 \mathrm{~mL}$ of $1 \%$ lidocaine was given prior to lesioning through each cannula. Lesioning then took place at $80^{\circ} \mathrm{C}$ if an 18 -gauge cannula was used and $90^{\circ} \mathrm{C}$ if a 20 -gauge cannula was used, both for 90 seconds. After lesioning, $1 \mathrm{~mL}$ of a solution containing $4 \mathrm{~mL}$ of $0.25 \%$ bupivacaine plus $1 \mathrm{~mL}$ of triamcinolone $(40 \mathrm{mg} / \mathrm{mL})$ was given through each cannula. 


\section{Outcome measures}

The patient's age, sex, and ethnicity were collected for demographic purposes. Each patient's chart was assessed to determine whether the patient underwent an early Australian versus advanced Australian facet radiofrequency denervation technique. Additionally, the lumbar levels at which each patient was treated with radiofrequency ablation were recorded. The primary outcome measures were 1-month postprocedure visual numeric scale (VNS) pain scores and VNS pain-score difference. ${ }^{20}$ Secondary outcome measures included: 1) patient self-reported improvement in pain following their radiofrequency denervation as noted in the patient's medical records, 2) adverse reactions and events related to the procedure, 3) pain-medicine consumption prior to and after the procedure, 4) the need for any subsequent, nonfacet denervation, pain-related intervention for the treatment of low-back pain, and 5) time to initial recurrence of a patient's facet pain following radiofrequency denervation.

Patients that reported resolution of their pain at their 1-month postprocedural clinic visit but were subsequently lost to follow-up were classified as having resolution of their pain. In these patients, the time frame between their radiofrequency denervation procedure and their last clinic visit was reported as the duration of pain relief. For all other patients, the duration of pain relief was determined from subsequent follow-up visits reporting recurrence of the patient's lumbar facet pain.

\section{Statistical analysis}

To analyze the efficacy of the early Australian technique compared to the advanced Australian technique, Student's $t$-tests were used to compare pre- and postablation VNS test scores as well as change in VNS test scores between groups. An assessment of the distribution of the VNS scores for the early Australian and advanced Australian techniques was performed to ensure a Gaussian distribution. To compare the subjective benefit rates reported between patients of the two groups, a $\chi^{2}$ test was performed. As the duration of relief between the two groups did not follow a normal distribution, a Wilcoxon rank-sum test was performed to determine whether a difference existed between the two groups. Time to recurrence was plotted using the Kaplan-Meier method, and the resulting curves were compared between groups using the log-rank test. Cox proportional hazard analysis was utilized to construct a regression model for the recurrence time and to assess the contribution of technique, as well as to adjust for patient-demographic factors. Logistic and linear regression analyses were performed to model patient-reported improvement in pain and VNS outcome scores, respectively, to adjust for the effect of demographic variables in addition to treatment technique. To ensure model validity, interaction effects were tested in the regression models, and an examination of outliers was performed. Postprocedural complications and the need for nonablative follow-up procedures were summarized for each group, and a $\chi^{2}$ analysis was performed to compare rates of these events between groups.

\section{Results}

A total of 373 patients underwent lumbar facet denervation between the years of 2008 and 2012. Ninety-four patients were treated with the advanced Australian technique, while 279 patients were treated with the early Australian technique. However, 12 patients in the advanced Australian group and 38 patients in the early Australian group were excluded from the inclusion cohort due to lack of data or follow-up. Demographic data for the two groups are listed in Table 1. The average age was 57.8 and 60.5 years for the advanced Australian and early Australian groups, respectively. The sex breakdown for these two groups was $41.5 \%$ male in the advanced Australian group and $36.1 \%$ in the early Australian group. For all demographic data, no statistically significant differences were noted, with the exception of a greater percentage of Asian patients in the advanced Australian group compared to the early Australian group $(P=0.001)$.

Table I Demographic data comparing the Advanced Australian and the Early Australian techniques

\begin{tabular}{|c|c|c|c|c|}
\hline & & $\begin{array}{l}\text { Advanced Australian } \\
\text { technique (82) }\end{array}$ & $\begin{array}{l}\text { Early Australian } \\
\text { technique (24I) }\end{array}$ & P-value \\
\hline \multirow[t]{5}{*}{ Ethnicity (n [\%]) } & Caucasian & $50(61.0 \%)$ & 185 (76.8\%) & 0.01 \\
\hline & African-American & $4(4.9 \%)$ & $22(9.1 \%)$ & \\
\hline & Asian & 16 (19.5\%) & $3(1.2 \%)$ & \\
\hline & Hispanic & 7 (8.5\%) & $24(10.0 \%)$ & \\
\hline & Middle eastern & $5(6.1 \%)$ & $7(2.9 \%)$ & \\
\hline \multirow[t]{2}{*}{$\operatorname{Sex}(n[\%])$} & Male & 34 (4I.5\%) & 87 (36.1\%) & 0.39 \\
\hline & Female & $48(58.5 \%)$ & I54 (63.9\%) & \\
\hline Mean age & Years (standard deviation) & $57.8(15.9)$ & $60.5(15.0)$ & 0.17 \\
\hline
\end{tabular}


Table 2 Analysis of primary and secondary outcome measures

\begin{tabular}{|c|c|c|c|c|}
\hline & & $\begin{array}{l}\text { Advanced Australian } \\
\text { technique (82) }\end{array}$ & $\begin{array}{l}\text { Early Australian } \\
\text { technique (24I) }\end{array}$ & P-value \\
\hline \multirow[t]{6}{*}{ VNS data ${ }^{a}$} & Preablation Mean VNS & $6.45(1.77)$ & $6.55(1.78)$ & 0.72 \\
\hline & Preablation Median VNS & $7(5-8)$ & $7(5-8)$ & \\
\hline & Postablation Mean VNS & $3.64(2.4 I)$ & $4.27(2.7 I)$ & 0.06 \\
\hline & Postablation Median VNS & $3.75(1.75-5)$ & $4(2-6)$ & \\
\hline & Mean VNS difference & $2.82(2.30)$ & $2.28(2.54)$ & 0.08 \\
\hline & Median VNS difference & $3(I-6)$ & $2.5(0-6)$ & \\
\hline Benefit $(\mathrm{n}[\%])^{\mathrm{b}}$ & Yes & $70(85.4 \%)$ & $170(70.5 \%)$ & 0.012 \\
\hline Relief $^{c}$ & Median duration (months) & $4.0(2,6)$ & $\mathrm{I} .5(\mathrm{I}, 2)$ & 0.022 \\
\hline \multirow[t]{2}{*}{ Complications (n [\%]) ${ }^{d}$} & All complications (events) & $8(9.8 \%)$ & $16(6.6 \%)$ & 0.37 \\
\hline & Neuritis (events) & $3(3.7 \%)$ & $6(2.5 \%)$ & 0.58 \\
\hline Follow-up procedure (n [\%]) ${ }^{d}$ & Yes & 27 (32.9\%) & $67(27.8 \%)$ & 0.38 \\
\hline
\end{tabular}

Notes: ${ }^{a} \mathrm{~A}$ t-test analysis was used to compare pre- and postablation VNS score changes, as well as VNS score differences between the advanced Australian and early Australian techniques; benefit reported between the advanced Australian and early Australian groups assessed using $\chi^{2}$ analysis; 'duration of relief between the two treatment groups assessed using log-rank analysis; 'comparison of complications and need for follow-up procedures was assessed using $\chi^{2}$ analysis.

Abbreviation: VNS, visual numeric scale.

The advanced Australian and early Australian groups showed comparable baseline VNS pain scores, 6.45 and 6.55 , respectively, with no statistical difference between the two groups (Table 2). Neither the postablative VNS pain scores nor the VNS pain-score differences from preablation to postablation for the two groups reached a statistically significant level based on $t$-test analysis.

To further assess the efficacy of early Australian and advanced Australian techniques on pain relief, a qualitative assessment of patients' self-reported pain relief was performed. Overall, a significantly larger percentage of patients in the advanced Australian group reported pain relief ( $85.4 \%$ versus $70.5 \%, P=0.012$ ) (Table 2). The need for nonablative interventional pain procedures (epidural steroid injections, sacroiliac joint injections, piriformis injections) to further treat the patient's pain syndrome was also assessed. The advanced Australian group had a slightly higher but not statistically significant follow-up procedure rate of $32.9 \%$ versus the $27.8 \%$ of the early Australian group $(P=0.38)$ (Table 2$)$. The majority of postablation procedures consisted of an epidural steroid injection, a sacroiliac joint injection, or a piriformis injection, with $89 \%$ and $73 \%$ of follow-up procedures consisting of one of these three injections in the advanced Australian and early Australian groups, respectively.

An assessment of the risk of complications between the advanced Australian and early Australian techniques showed that complications, including bruising, infection, paresthesias, neuritis, and muscle spasms, occurred in roughly $9.8 \%$ and $6.6 \%$ of patients in the advanced Australian and early Australian groups, respectively $(P=0.37)$. To better assess the risk of postdenervation neuritis, a $\chi^{2}$ analysis of this single complication was performed, with both groups showing similar occurrence rates of $3.7 \%$ and $2.5 \%(P=0.58)$ (Table 2).
In addition to analysis of initial pain relief obtained from undergoing a lumbar facet denervation for the treatment of lumbar facet pain, the duration of relief was measured. In the advanced Australian group, 62 of 82 (75.7\%) patients had documented recurrence of their pain, while 208 of $241(82.3 \%)$ of patients in the early Australian group had documented recurrence of their pain. A Kaplan-Meier curve was plotted to assess statistical difference between the two groups (Figure 1). Immediate procedural treatment failure was higher in the early Australian group, with $50 \%$ of all patients in this group showing initial recurrence of pain by 1.5 months. In contrast, the advanced Australian group showed that $50 \%$ of patients continued to remain pain-free until 4 months. This difference in duration of treatment effect was statistically significant $(P=0.022)$. However, by 11 months postprocedure, the difference in pain relief between the advanced Australian and

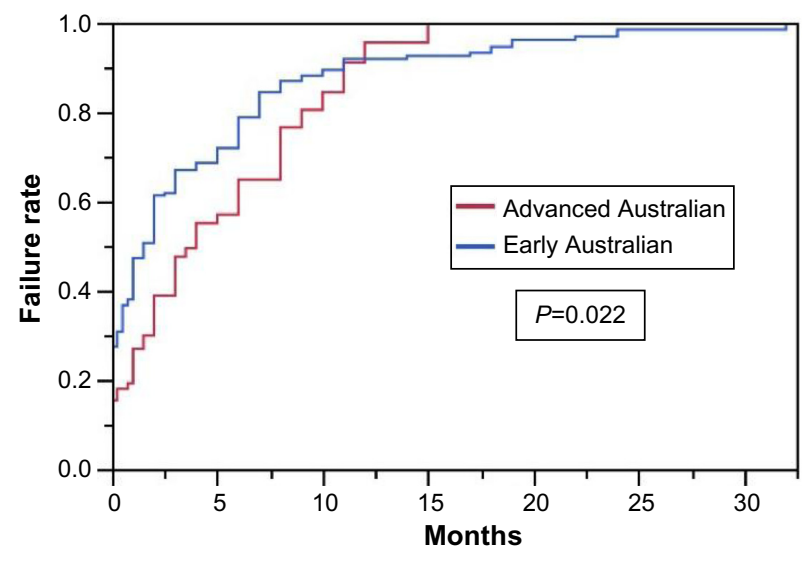

Figure I Kaplan-Meier curve showing failure rate over time in months between the advanced Australian and early Australian groups.

Note: A statistically significant difference between the two groups was determined based on a $P$-value of 0.022 calculated using a log-rank test. 
Table 3 Cox proportional hazard analysis for individual variables and their effect on recurrence of patient pain

\begin{tabular}{llll}
\hline Factors & Category & $\begin{array}{l}\text { Hazard ratio (95\% } \\
\text { confidence interval) }\end{array}$ & P-value \\
\hline Age (years) & & $1.00(0.99,1.0 I)$ & 0.77 \\
Sex (male) & Male & $0.99(0.87,1.13)$ & 0.91 \\
Ethnicity (Caucasian) & Caucasian & $0.96(0.84, I . I I)$ & 0.55 \\
Treatment group & Advanced & $0.83(0.71,0.96)$ & 0.01 \\
(Advanced Australian) & Australian & & \\
Preablation VNS & & $\mathrm{I} .04(0.97,1.12)$ & 0.25 \\
Pain medication (No) & No & $0.91(0.78,1.06)$ & 0.23 \\
\hline
\end{tabular}

Abbreviation: VNS, visual numeric scale.

early Australian groups became negligible, with nearly $90 \%$ of all patients in both groups reporting recurrence of their pain to preablation levels.

The effects of demographic variables influencing the duration of pain relief were assessed using a Cox proportional hazard model (Table 3). Of the demographic factors analyzed, only the treatment group showed a significant difference $(P=0.01)$. The effect of treatment group showed that the advanced Australian technique was associated with less failure to treat for patients undergoing a lumbar facet denervation procedure, with a hazard ratio of 0.83 ( $95 \%$ confidence interval [CI] 0.71-0.96). The effects of age, sex, ethnicity, preablation VNS pain score, and pain-medication consumption were all statistically nonsignificant.

A linear regression analysis evaluating variables' effect on postablation VNS scores was performed, with age, sex, preablation VNS pain score, and pain-medication usage showing importance. Sex, preablation VNS pain score, and pain-medication usage showed statistical significance, while age demonstrated near-statistical significance (Table 4). Age and preablation VNS demonstrated a positive correlation with postablation VNS scores, with increases in age and preablation VNS scores resulting in increased postablation scores. Sex and preablation pain-medication use had a negative correlation with postablation VNS scores, with male sex and no pain-medication use being associated with a decreased postablation VNS score (Table 4).

Table 4 Linear regression model with postablation VNS pain score as the outcome measure

\begin{tabular}{lll}
\hline Factors & $\begin{array}{l}\text { Coefficient } \\
\text { (standard error) }\end{array}$ & P-value \\
\hline Age (years) & $0.02(0.01)$ & 0.08 \\
Sex (male) & $-0.31(0.15)$ & 0.03 \\
Preablation VNS & $0.58(0.08)$ & $<0.01$ \\
Pain-medication use (n) & $-0.41(0.17)$ & 0.02 \\
Treatment group (Advanced & $-0.20(0.17)$ & 0.22 \\
Australian) & & \\
\hline
\end{tabular}

Abbreviation: VNS, visual numeric scale.
Table 5 Logistic regression model with patient self-reported procedural benefit as the outcome measure

\begin{tabular}{lll}
\hline Factors & $\begin{array}{l}\text { Odds ratio (95\% } \\
\text { confidence interval) }\end{array}$ & P-value \\
\hline Age (Years) & $1.02(1.00,1.04)$ & 0.04 \\
Group (Advanced Australian) & $1.46(1.04,2.06)$ & 0.03 \\
\hline
\end{tabular}

A logistic regression analysis revealed that age and treatment group were significantly associated with patient selfreported procedural benefit (Table 5). Age demonstrated a positive correlation with patient self-reported benefit, with an odds ratio of 1.02 (95\% CI 1.00-1.04), indicating a greater chance of subjective patient-reported benefit as patients became older. The effect of treatment group on outcome demonstrated that the advanced Australian technique produced better patient-reported outcomes, with an odds ratio of 1.46 (95\% CI 1.04-2.06). To assess the prediction accuracy of the logistic regression analysis, a receiver operating characteristic curve was plotted, with a calculated area under the curve of 0.6138 (Figure 2).

\section{Discussion}

Currently, no comparative studies exist evaluating the efficacy and safety of different lumbar facet joint-denervation needle-placement techniques for the treatment of lumbar facet arthropathy pain. A study by Lau et al demonstrated the anatomic pathway of medial branch nerve innervation for the lumbar facet joints, arguing that parallel placement (advanced Australian technique) of the radiofrequency probes

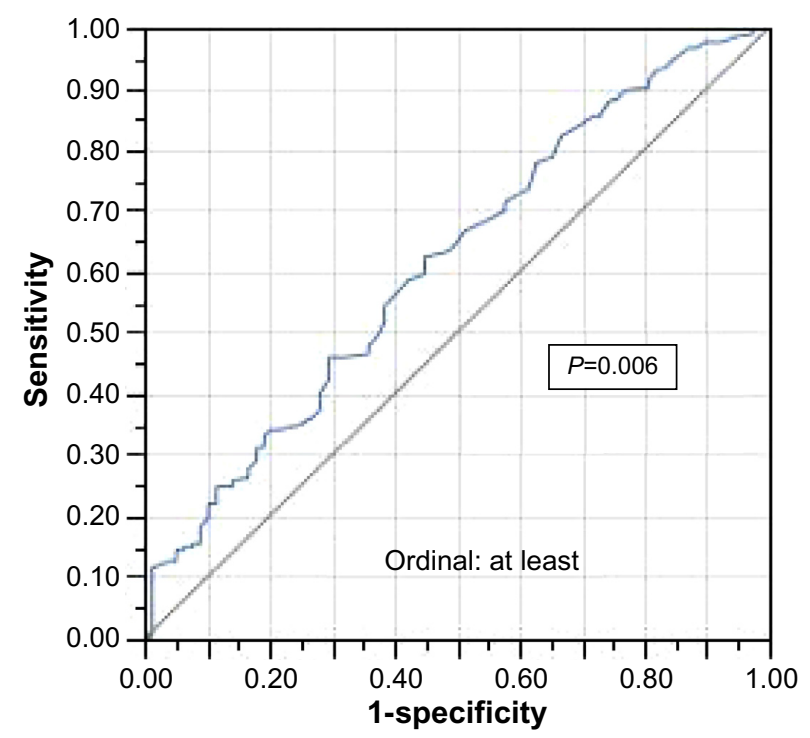

Figure $\mathbf{2}$ Logistic regression receiver operating characteristic curve. Area under the curve calculated to be 0.6138 .

Notes: The gray line is the control line for uniformative ROC curve. The blue line represents the ROC curve for predictive value of our logistic regression model. 
against the medial branch nerves is key to successful treatment of facet arthropathy. ${ }^{18}$ Based on the anatomic finding in this study, Lau et al ${ }^{18}$ hypothesized that many lumbar facet denervation techniques fail to appropriately ablate the nervous innervation to the lumbar facet joints, as they are not placed parallel to the medial branch nerves. A recent review by Gofeld and Faclier also supported an anatomically appropriate radiofrequency needle-placement technique and reported on the paucity of research available using the correct anatomic technique. ${ }^{19}$ The goal of the current study was retrospectively to evaluate and validate the hypothesis that the advanced Australian technique is superior to the early Australian technique based on the anatomic findings of Lau et al. ${ }^{18}$

In the present study, the magnitude and duration of pain relief reported by patients were found to be greater in patients treated with the advanced Australian versus the early Australian technique. This outcome is consistent with the findings detailed in a study by Dreyfuss et al. ${ }^{12}$ However, Dreyfuss et a $\mathrm{l}^{12}$ demonstrated prolonged benefit with the use of the advanced Australian technique in appropriately selected patients. The present study failed to replicate the lasting beneficial effects seen within the Dreyfuss et al ${ }^{12}$ study, as patients demonstrated median initial recurrence of pain by 1.5 months and 4 months within the early Australian and advanced Australian groups, respectively. By 12 months, $90 \%$ of patients in both groups demonstrated recurrence of their pain to preablation levels (Figure 1), which is noticeably different than the $60 \%-80 \%$ of patients that continued to experience pain relief at 12 months within the Dreyfuss et al study. ${ }^{12}$ While the duration of pain relief in the two groups was shorter compared to this study, the pain relief obtained for both groups was clinically beneficial. Both groups experienced a decrease in VNS pain scores of greater than 2 points, which is a clinically relevant result, ${ }^{21}$ though the change in VNS scores between the two groups did not reach a statistically significant difference.

Possible explanations for the lack of prolonged benefit experienced by patients in this study are: 1) performance of the procedure in a teaching institution, 2) the possibility of false-positive diagnostic blockade associated with single medial branch blocks, ${ }^{22}$ 3) the multifactorial nature of low-back pain, and 4) aberrant nerve sprouting. Clinical studies for diagnostic blocks for facet joint pain have reported a high incidence of false-positive results, with up to $41 \%$ incidence in the lumbar spine. ${ }^{12,23,24}$ Multiple factors can account for such a high false-positive rate, including a high rate of response to placebo injections, ${ }^{25}$ inappropri- ate use of sedation ${ }^{26}$ or superficial local anesthetic, ${ }^{27}$ and spread of the injectate to other structures that can generate pain. ${ }^{28,29}$ Therefore, false-positive responses to diagnostic medial branch blocks could potentially explain our results. Furthermore, the causes of low-back pain range from facet arthropathy, spinal stenosis, and radiculopathies to muscular and fascial etiologies. In many patients, facet arthropathy, spinal stenosis, and lumbar radiculopathy coexist. Therefore, the presence of comorbidities results in only partial treatment of a patient's low-back pain. In the present study, the presence of comorbidities could potentially explain the lack of prolonged benefit and immediate failure rates of $12.8 \%$ and $25.4 \%$ in the advanced Australian and early Australian groups, respectively. Okuyama et al showed that radiofrequency ablation in cardiac tissue results in aberrant nerve sprouting within 2 hours after ablation. Therefore, ablation of nerves within the back has a high likelihood for a similar development, which could cause faster failure rates. ${ }^{30}$

With regard to the demographic differences between the advanced Australian and early Australian groups, the only significant difference was the ethnic groups represented. The advanced Australian group had an Asian population of $19 \%$ versus $1.1 \%$ in the early Australian group $(P=0.001)$. However, the outcomes observed were not influenced by ethnicity. Results of the Cox proportional hazard model showed that only the treatment group significantly affected the recurrence rate of a patient's pain $(P=0.01)$, with ethnicity having a $P$-value of 0.55 . A linear regression analysis modeled on postablation VNS scores only showed age, sex, preablation VNS score, and pain medication as significant factors. Similarly, a logistic regression analysis found age and treatment group to be significantly correlated with patient pain relief. Therefore, while the ethnic breakdown between groups was statistically different, this difference did not affect the outcomes observed.

Within the linear regression analysis, age and preablation VNS score had a positive correlation with increased postprocedural VNS scores. The lumbar spine of an aging individual is subject to increased degenerative processes, which increase the likelihood for the development and potential severity of low-back pain. Therefore, clinically, one could anticipate that the treatment of facet arthropathy may be more difficult in elderly patients as they have more potential sources for pain, resulting in higher postablation VNS scores. Similarly, if the ablative procedure confers the same degree of benefit within individuals, an individual with a higher preablation VNS score will likely have higher postablation VNS scores. However, in practice, this may not 
always be true, as appropriate treatment in those with a higher initial VNS score could give rise to a greater appreciation of pain relief and thus a lower pain score.

In contrast to the linear regression analysis, the logistic regression analysis found that only age and treatment group significantly impacted whether patients subjectively reported benefit from their lumbar facet denervation procedure. Increasing age was associated with an increased likelihood of patient-reported benefit, which is an interesting finding, considering that increased age was associated with increased postablative VNS pain scores in the linear regression analysis. Therefore, while older patients had higher postablative VNS scores, they also reported more benefit from denervation of their lumbar facet joints. This finding may suggest that the elderly, despite their higher postablative pain scores, can derive noticeable improvement in their overall condition after facet denervation. In the advanced Australian technique group, the odds ratio for patient self-reported procedural benefit was 1.46 times that of the early Australian technique. This finding further supports the hypothesis and anatomic studies that suggest the superiority of the advanced Australian technique over the early Australian technique.

Sex also appeared to play a role based on the Cox proportional hazard analysis, with male sex conferring a better outcome (hazard ratio 0.99). Therefore, within the linear regression analysis, the decrease in postablation VNS score of 0.312 for being male appears clinically appropriate. Similar to sex, patients not using pain medication had a hazard ratio of 0.91 measured by Cox proportional hazard analysis, compared to patients that did require use of pain medications. Therefore, it is logical that the linear regression-analysis outcome showing that patients who did not take pain medication at baseline had a postablation VNS score 0.408 points lower than in patients who did use pain medications at baseline.

In addition to evaluating the benefits of the advanced Australian and early Australian techniques in the treatment of lumbar facet pain, the safety of these two techniques was also assessed. The risk of complications was clinically significant, with both groups having a complication rate between $5 \%$ and $10 \%$. The two groups did not have a statistically significant difference in rate of complications based on $\chi^{2}$ analysis. While the advanced Australian technique is associated with closer placement of the radiofrequency ablative near the medial and dorsal branches of the nerve roots of the spine, the risk of postablative neuritis was not statistically different between the two groups.

Patient selection and technical factors can play a significant confounding role in the results of such a study as this. Given the study's retrospective nature, all the possible individual provider and patient factors that can affect patient selection and radiofrequency technique could not be controlled. By itself, radiofrequency technique can provide a difference in lesion volumes depending on the size of the radiofrequency cannula, the length of the active tip, the temperatures used, and the use of fluid modulation prior to lesioning. In our practice, there is uniformity among the providers with regard to using similar temperatures $\left(80^{\circ} \mathrm{C}-90^{\circ} \mathrm{C}\right)$, use of $1 \mathrm{~mL} 1 \%$ lidocaine as fluid modulation prior to lesioning, and all providers using 18- to 20-gauge needles all with a $10 \mathrm{~mm}$ active tip. Due to the uniformity of technique in our practice, the main difference in radiofrequency technique lies in the differing needle-placement techniques. This reduces but does not completely negate the possibility that patient-selection differences between providers or another aspect of radiofrequency technique are significantly confounding the results.

In conclusion, this retrospective study compared the efficacy and safety of the early Australian and advanced Australian facet radiofrequency-ablation techniques. The results of this study not only support the use of facet radiofrequency ablation in treatment of lumbar facet arthropathy due to improvement in pain scores and patient self-reported benefit but also strongly support the use of the anatomically correct advanced Australian technique when performing this procedure. Further large-scale, double-blind, randomized controlled trials evaluating efficacy using the advanced Australian technique are warranted to confirm the findings found in the present study.

\section{Acknowledgment}

The research and statistical analysis described was supported by NIH/National Center for Advancing Translational Science (NCATS) UCLA CTSI grant UL1TR000124.

\section{Disclosure}

The authors report no conflicts of interest in this work. Initial data analysis was presented at the American Society of Anesthesiologists Annual Meeting, Washington DC, October 13-17, 2012 and the American Society of Regional Anesthesia and Pain Medicine Fall Meeting, Miami, FL, November 15, 2012.

\section{References}

1. Turk DC. Clinical effectiveness and cost-effectiveness of treatment for patients with chronic pain. Clin J Pain. 2002;18(6):355-365.

2. Bogduk N. Low back pain. In: Bogduk N. Clinical and Radiological Anatomy of the Lumbar Spine. 5th ed. London: Elsevier; 2012.

3. Manusov EG. Evaluation and diagnosis of low back pain. Prim Care. 2012;39(3):471-479 
4. Schwarzer AC, Aprill CN, Derby R, Fortin J, Kine G, Bogduk N. The relative contributions of the disc and zygapophyseal joint in chronic low back pain. Spine (Phila Pa 1976). 1994;19(7):801-806.

5. Dreyer SJ, Dreyfuss PH. Low back pain and the zygapophysial (facet) joints. Arch Phys Med Rehabil. 1996;77(3):290-300.

6. van Kleef M, Vanelderen P, Cohen SP, Lataster A, Van Zundert J, Mekhail N. Pain originating from the lumbar facet joints. Pain Pract. 2010;10(5):459-469.

7. Andersson GB, Lucente T, Davis AM, Kappler RE, Lipton JA, Leurgans S. A comparison of osteopathic spinal manipulation with standard care for patients with low back pain. $N$ Engl J Med. 1999; 341(19):1426-1431.

8. Giles LG, Muller R. Chronic spinal pain: a randomized clinical trial comparing medication, acupuncture, and spinal manipulation. Spine (Phila Pa 1976). 2003;28(14):1490-1502; discussion 1502-1503.

9. Schnitzer TJ, Ferraro A, Hunsche E, Kong SX. A comprehensive review of clinical trials on the efficacy and safety of drugs for the treatment of low back pain. J Pain Symptom Manage. 2004;28(1):72-95.

10. van Kleef M, Barendse GA, Kessels A, Voets HM, Weber WE, de Lange S. Randomized trial of radiofrequency lumbar facet denervation for chronic low back pain. Spine (Phila Pa 1976). 1999; 24(18):1937-1942.

11. Nath S, Nath CA, Pettersson K. Percutaneous lumbar zygapophysial (facet) joint neurotomy using radiofrequency current, in the management of chronic low back pain: a randomized double-blind trial. Spine (Phila Pa 1976). 2008;33(12):1291-1297; discussion 1298.

12. Dreyfuss P, Halbrook B, Pauza K, Joshi A, McLarty J, Bogduk N. Efficacy and validity of radiofrequency neurotomy for chronic lumbar zygapophysial joint pain. Spine (Phila Pa 1976). 2000;25(10):1270-1277.

13. Leclaire R, Fortin L, Lambert R, Bergeron YM, Rossignol M. Radiofrequency facet joint denervation in the treatment of low back pain: a placebo-controlled clinical trial to assess efficacy. Spine (Phila Pa 1976). 2001;26(13):1411-1416; discussion 1417.

14. van Wijk RM, Geurts JW, Wynne HJ, et al. Radiofrequency denervation of lumbar facet joint in the treatment of chronic low back pain: a randomized, double-blind, sham lesion-controlled trial. Clin J Pain. 2005;21(4):335-344.

15. Bogduk N, Long DM. Percutaneous lumbar medial branch neurotomy: a modification of facet denervation. Spine (Phila Pa 1976). 1980; 5(2):193-200.

16. International Spine Intervention Society. Practice Guidelines for Spinal Diagnostic and Treatment Procedures. 2nd ed. San Rafael (CA): International Spine Intervention Society; 2013.
17. Bogduk N, Long DM. The anatomy of the so-called "articular nerves" and their relationship to facet denervation in the treatment of low-back pain. J Neurosurg. 1979;51(2):172-177.

18. Lau P, Mercer S, Govind J, Bogduk N. The surgical anatomy of lumbar medial branch neurotomy (facet denervation). Pain Med. 2004; 5(3):289-298

19. Gofeld M, Faclier G. Radiofrequency denervation of the lumbar zygapophysial joints - targeting the best practice. Pain Med. 2008; 9(2):204-211.

20. Ferreira-Valente MA, Pais-Ribeiro JL, Jensen MP. Validity of four pain intensity rating scales. Pain. 2011;152(10):2399-2404.

21. Farrar JT, Young JP Jr, LaMoreaux L, Werth JL, Poole RM. Clinical importance of changes in chronic pain intensity measured on an 11-point numerical pain rating scale. Pain. 2001;94(2):149-158.

22. Barnsley L, Lord S, Wallis B, Bogduk N. False-positive rates of cervical zygapophysial joint blocks. Clin J Pain. 1993;9(2):124-130.

23. Schwarzer AC, Wang SC, Bogduk N, McNaught PJ, Laurent R. Prevalence and clinical features of lumbar zygapophysial joint pain: a study in an Australian population with chronic low back pain. Ann Rheum Dis. 1995;54(2):100-106.

24. Manchikanti L, Pampati V, Fellos B, Bakhit CE. Prevalence of lumbar facet joint pain in chronic low back pain. Pain Physician. 1999; 2(3):59-64.

25. Lord SM, Barnsley L, Bogduk N. The utility of comparative local anesthetic blocks versus placebo-controlled blocks for the diagnosis of cervical zygapophysial joint pain. Clin J Pain. 1995;11(3):208-213.

26. Manchikanti L, Damron KS, Rivera JJ, et al. Evaluation of the effect of sedation as a confounding factor in the diagnostic validity of lumbar facet joint pain: a prospective, randomized, double-blind, placebocontrolled evaluation. Pain Physician. 2004;7(4):411-417.

27. Ackerman WE, Munir MA, Zhang JM, Ghaleb A. Are diagnostic lumbar facet injections influenced by pain of muscular origin? Pain Pract. 2004;4(4):286-291.

28. Dreyfuss P, Schwarzer AC, Lau P, Bogduk N. Specificity of lumbar medial branch and L5 dorsal ramus blocks. A computed tomography study. Spine (Phila Pa 1976). 1997;22(8):895-902.

29. Cohen SP, Strassels SA, Kurihara C, et al. Randomized study assessing the accuracy of cervical facet joint nerve (medial branch) blocks using different injectate volumes. Anesthesiology. 2010;112(1):144-152.

30. Okuyama Y, Pak HN, Miyauchi Y, et al. Nerve sprouting induced by radiofrequency catheter ablation in dogs. Heart Rhythm. 2004;1(6): $712-717$.
Journal of Pain Research

\section{Publish your work in this journal}

The Journal of Pain Research is an international, peer-reviewed, open access, online journal that welcomes laboratory and clinical findings in the fields of pain research and the prevention and management of pain. Original research, reviews, symposium reports, hypothesis formation and commentaries are all considered for publication.
Dovepress

The manuscript management system is completely online and includes a very quick and fair peer-review system, which is all easy to use. Visit http://www.dovepress.com/testimonials.php to read real quotes from published authors. 